\title{
Erratum to: External validation of clinical decision rules for children with wrist trauma
}

\author{
Marjolein A. M. Mulders ${ }^{1} \cdot$ Monique M. J. Walenkamp ${ }^{1} \cdot$ Bente F. H. Dubois $^{1}$ • \\ Annelie Slaar $^{2}$ • J. Carel Goslings ${ }^{1}$. Niels W. L. Schep ${ }^{3}$
}

Published online: 12 April 2017

(C) Springer-Verlag Berlin Heidelberg 2017

Erratum to: Pediatr Radiol (2017)

DOI 10.1007/s00247-017-3787-z

The published version of this article contained mistakes. Table 6 was published with incorrect table heading and table legend. This has now been corrected. The Publisher apologizes for the mistakes and the inconvenience caused.

Table 6 Missed fractures

\begin{tabular}{llllll}
\hline & Pershad et al. & Webster et al. & Rivara et al. & APWR & Total (+APWR) \\
\hline Distal radius & 2 & 0 & 2 & 1 & $4(5)$ \\
Greenstick & 1 & 1 & 1 & 0 & $3(3)$ \\
Torus distal radius & 3 & 0 & 2 & 6 & $5(11)$ \\
Epiphysiolysis distal radius & 2 & 1 & 2 & 0 & $5(5)$ \\
Antebrachii & 0 & 0 & 0 & 0 & $0(0)$ \\
Ulna & 0 & 0 & 0 & 0 & $0(0)$ \\
Total & 8 & 2 & 7 & 7 & $17(24)$ \\
\hline
\end{tabular}

APWR Amsterdam Pediatric Wrist Rules

The online version of the original article can be found at http://dx.doi. org/10.1007/s00247-017-3787-z

Marjolein A. M. Mulders

m.a.mulders@amc.nl

Trauma Unit, Department of Surgery, Academic Medical Center, Meibergdreef 9, 1105 AZ Amsterdam, The Netherlands

2 Department of Radiology, Academic Medical Center, University of Amsterdam, Amsterdam, The Netherlands

3 Department of Surgery, Maasstad Hospital, Rotterdam, The Netherlands 